\title{
Evidence that the rate-limiting step for the biosynthesis of arachidonic acid in Mortierella alpina is at the level of the 18:3 to 20:3 elongase
}

\author{
James P. Wynn and Colin Ratledge
}

Lipid Research Group, Department of Biological Sciences, University of Hull, Hull HU6 7RX, UK
Author for correspondence: James P. Wynn. Tel: +44 1482 465507. Fax: +44 1482465458. e-mail: j.p.wynn@biosci.hull.ac.uk

\begin{abstract}
Mortierella alpina, a fungus used commercially as a source of arachidonic acid, 20:4(n-6), has been examined to see if growth on lipid-based carbon sources leads to repression of either fatty acid biosynthesis and/or fatty acid desaturation and elongation. Changes in the activities of ATP: citrate lyase, isocitrate lyase, carnitine acetyltransferase, malic enzyme, glucose-6phosphate dehydrogenase and pyruvate kinase when the fungus was grown on fatty-acid-based (Tween) carbon sources were consistent with (i) the cells using the fatty acyl portion of the substrate as the sole carbon source, (ii) pyruvate kinase being the source of pyruvate for biosynthesis under these conditions and (iii) malic enzyme's major function being as a provider of NADPH for lipid biosynthesis. The abolition of fatty acid synthase activity when cells were grown on Tweens indicated the cessation of de novo fatty acid biosynthesis under these conditions. The fatty acyl composition of the lipid accumulated by the fungus grown on Tweens 20, 40 and 80 showed that desaturation and elongation of the substrate lipid still occurred. The absolute amount of arachidonic acid synthesized by Tween-grown cells was the same as for cells grown on glucose. The transformation of incorporated fatty acids into $20: 4(n-6)$ was, it appeared, limited at the elongation of $18: 3(n-6)$ to $20: 3(n-6)$ as, in every case, 18:1, 18:2 and 18:3(n-6) increased in amount in the Tweengrown cells. These data show for the first time that fatty acid synthesis is regulated separately from fatty acid desaturation/elongation and that the latter reactions are not repressed by growth of the fungus on simple fatty acids. Furthermore, the data strongly implicate the elongation of $18: 3(n-6)$ to 20:3(n-6) as the limiting step in arachidonic acid biosynthesis by Mort. alpina.
\end{abstract}

Keywords: fatty acid desaturation, fatty acyl chain-elongation systems, lipid metabolism, Mortierella alpina

\section{INTRODUCTION}

Arachidonic acid, 20:4(n-6), is a very long chain polyunsaturated fatty acid (VLC-PUFA) whose importance in neonatal nutrition, particularly for neural development, has been highlighted (Kyle, 1997). No convenient plant or animal source for the commercial production of this VLC-PUFA is available (Ratledge, 1997). As a result, arachidonic acid is one of only two single cell oils (oils produced using microorganisms; Ratledge, 1992) currently in production (Gill

Abbreviation: PUFA, polyunsaturated fatty acid.
\& Valivety, 1997). The organism employed in the production of arachidonic-acid-rich oil is a zygomycete fungus, Mortierella alpina, which can accumulate up to $40 \%$ (w/w) lipid, of which up to $40 \%$ can be arachidonic acid, when cultivated in submerged culture in a fermenter with glucose as a carbon source (Wynn et al., 1999).

There is interest in using Mort. alpina as a biocatalyst for the biotransformation of low-value oils (such as sunflower oil) rich in 18:2 into higher-value oils, such as those that are rich in $20: 4(n-6)$. Biotransformation of exogenous oils by Mort. alpina has been reported previously (Shimizu et al., 1989a, b; Shinmen et al., 
1992; Certik et al., 1997). These data are somewhat contentious, however, because of: (a) the possibility of 'carry over' of exogenous lipid substrate adhering to the cells during their harvesting; (b) the possibility of continued de novo synthesis of PUFAs by the cells (albeit at a low level, but never previously measured in this organism); or (c) selective uptake of particular PUFAs from the mixed fatty acids used as the carbon source (Certik et al., 1997). Furthermore, work in this laboratory suggested that growth of four filamentous fungi, although not Mort. alpina itself, on exogenous lipid caused a down-regulation of all fatty acid desaturation and elongation processes (Kendrick \& Ratledge, 1996).

No studies, as far as we are aware, have been carried out using ${ }^{14} \mathrm{C}$ - or ${ }^{13} \mathrm{C}$-labelled substrates, which would have provided unequivocal evidence for continuing desaturation and elongation reactions when filamentous fungi are cultivated on exogenous oils. The present study aimed to clarify some of the more equivocal findings of the previous studies by using a combination of enzymology and lipid analysis of Mort. alpina cultivated on glucose and a range of water-soluble, lipid-based carbon sources, the Tweens, that can easily be washed off cells, thereby preventing unwanted 'carry over' of the substrate fatty acids. Tweens are polyesters of sorbitan and fatty acids; when they are hydrolysed, by lipase/esterases, only the fatty acids are available; sorbitan is not a substrate for this fungus.

\section{METHODS}

Chemicals. Unless otherwise stated, all fine chemicals were purchased from Sigma. Tween 20 is polyoxyethylenesorbitan monolaurate $(\approx 55 \% 12: 0)$, Tween 40 is polyoxyethylenesorbitan monopalmitate $(\approx 95 \% 16: 0)$ and Tween 80 is polyoxyethylenesorbitan monooleate ( $\approx 70 \% 18: 1)$; see Table 1.

Maintenance and cultivation of Mort. alpina. Mort. alpina Peyron CBS 696.70 was maintained on plates on Kendrick medium (Kendrick \& Ratledge, 1992) solidified with $2 \%$ $(\mathrm{w} / \mathrm{w})$ agar (Oxoid). Plates were incubated at $30^{\circ} \mathrm{C}$ for $7 \mathrm{~d}$ and stored at $4{ }^{\circ} \mathrm{C}$. The fungus was grown on defined Kendrick medium (no yeast extract), with glucose $\left(30 \mathrm{~g} \mathrm{l}^{-1}\right)$ or Tween 20 , 40 or $80\left(16 \mathrm{~g} \mathrm{l}^{-1}\right)$ as the carbon source, in 1 litre shake flasks containing $200 \mathrm{ml}$ medium. Flasks were inoculated with $1 \mathrm{ml}$ of a mycelial suspension, produced by agitating a $1 \times 1 \mathrm{~cm}$ plug from a maintenance plate with $10 \mathrm{ml}$ distilled water and 10 glass beads ( $3 \mathrm{~mm}$ diameter). The flasks were incubated at $27^{\circ} \mathrm{C}$ with shaking at 145 r.p.m. for $7 \mathrm{~d}$.

Preparation of cell extracts. Biomass was harvested by filtration (under reduced pressure) through a Whatman no. 1 paper and washed extensively with distilled $\mathrm{H}_{2} \mathrm{O}$. The mycelia

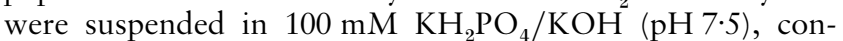
taining $20 \%(\mathrm{w} / \mathrm{v})$ glycerol, $1 \mathrm{mM}$ benzamidine. $\mathrm{HCl}$ and $1 \mathrm{mM}$ dithiothreitol, and disrupted by passage, twice, through a French pressure cell at $35 \mathrm{MPa}$. The resulting extract was centrifuged at $16000 \mathrm{~g}$ for $10 \mathrm{~min}$ at $4{ }^{\circ} \mathrm{C}$ and the supernatant retained for analysis. Protein concentrations were determined using the method of Bradford with BSA as a standard.

Determination of enzyme activities. All enzymes were assayed using previously published procedures. Isocitrate lysase (EC 4.1.3.1) was assayed as described by Armitt et al. (1976), ATP:citrate lyase (EC 4.1.3.8), fatty acid synthase (EC
Table 1. Fatty acyl composition of the Tween carbon sources

The fatty acyl composition of Tween 20, 40 and 80 was determined by GC analysis of fatty acid methyl esters, prepared as described by Butte (1983). Fatty acid methyl esters were identified by comparison with authentic standards.

\begin{tabular}{|lccc|}
\hline Fatty acyl residue & \multicolumn{3}{c|}{ Relative $\%(\mathbf{w} / \mathbf{w})$ of total fatty acids } \\
\cline { 2 - 4 } & Tween 20 & Tween 40 & Tween 80 \\
\hline $12: 0$ & $55 \cdot 4$ & $0 \cdot 0$ & $0 \cdot 6$ \\
$14: 0$ & $19 \cdot 6$ & $0 \cdot 4$ & $3 \cdot 0$ \\
$16: 0$ & $10 \cdot 2$ & $94 \cdot 0$ & $5 \cdot 6$ \\
$16: 1$ & $0 \cdot 0$ & $0 \cdot 0$ & $5 \cdot 1$ \\
$18: 0$ & $9 \cdot 5$ & $3 \cdot 3$ & $2 \cdot 4$ \\
$18: 1$ & $4 \cdot 2$ & $1 \cdot 3$ & $71 \cdot 3$ \\
$18: 2$ & $0 \cdot 5$ & $0 \cdot 5$ & $1 \cdot 0$ \\
$18: 3(n-6)$ & - & - & $0 \cdot 4$ \\
$18: 3(n-3)$ & - & - & $0 \cdot 6$ \\
$20: 3(n-6)$ & - & - & - \\
$20: 4(n-6)$ & - & - & - \\
UI* & $0 \cdot 07$ & $0 \cdot 04$ & $0 \cdot 81$ \\
\hline
\end{tabular}

$*$ UI (unsaturation index $)=\left[\begin{array}{lll}\% & \text { monoene }+2(\% & \text { diene })+3(\%\end{array}\right.$ triene $)+4(\%$ tetraene $)] / 100$.

2.3.1.85), glucose-6-phosphate dehydrogenase (EC 1.1.1.49), and malic enzyme (EC 1.1.1.40) as described by Wynn et al. (1997), carnitine acetyltransferase (EC 2.3 .1.7) as described by Kawamoto et al. (1978), and pyruvate kinase (EC 2.7.1.40) as described by Worthington Enzymes (1979).

Lipid analysis. Washed biomass was freeze-dried and lipid analysis carried out using two separate protocols. In the first protocol, the cell lipid was extracted with 2:1 (v/v) chloroform/methanol (Folch et al., 1957) and quantified gravimetrically. If this method was employed, the fatty acyl composition of the cell lipid was determined by GC analysis of fatty acid methyl esters, prepared using trimethylsulphonium hydroxide as described by Butte (1983). In the second protocol, the cell lipid was extracted and methylated in a single step as described by Rodriguez-Ruiz et al. (1998) and quantified by reference to a 17:0 internal standard. The fatty acyl composition of the cell lipid was analysed using an ATI Unicam 610 series GC fitted with a $25 \mathrm{~m}, 0.5 \mu \mathrm{m}$, fused silica BPX70 column (SGE). The detector and injector temperatures were $300{ }^{\circ} \mathrm{C}$ and $250{ }^{\circ} \mathrm{C}$ respectively and the oven temperature was increased from $100{ }^{\circ} \mathrm{C}$ to $200^{\circ} \mathrm{C}$ in $10 \mathrm{~min}$ then maintained at $200{ }^{\circ} \mathrm{C}$ for a further $5 \mathrm{~min}$. Fatty acid methyl esters were identified by comparison with authentic standards.

Reproducibility of data. All experiments were carried out in triplicate at least and data are presented as mean values \pm standard error of the mean.

\section{RESULTS AND DISCUSSION}

\section{Changes in key enzyme activities when Mort. alpina is grown on glucose or Tween $\mathbf{8 0}$}

Isocitrate lyase. This is a marker enzyme for the glyoxylate bypass of the citric acid cycle which is induced in cells grown on carbon sources that are metabolized 
Table 2. Enzyme activities in Mort. alpina cultivated on glucose or Tween 80

Biomass was cultivated in shake flasks for $4 \mathrm{~d}$ at $30{ }^{\circ} \mathrm{C}$ on a defined medium containing either $30 \mathrm{~g}$ glucose $\mathrm{l}^{-1}$ or $16 \mathrm{~g}$ Tween $80 \mathrm{l}^{-1}$ as the carbon source. Data presented are mean values \pm standard error of the mean $(n \geqslant 3)$.

\begin{tabular}{|c|c|c|}
\hline \multirow[t]{2}{*}{ Enzyme } & \multicolumn{2}{|c|}{$\begin{array}{l}\text { Activity }\left[\mathrm{nmol} \mathrm{min}^{-1}(\mathrm{mg}\right. \\
\left.\text { protein })^{-1}\right] \text { after growth on: }\end{array}$} \\
\hline & Glucose & Tween 80 \\
\hline Isocitrate lyase & nil & $48 \cdot 2 \pm 10 \cdot 7$ \\
\hline ATP: citrate lyase & $27 \pm 10$ & nil \\
\hline Carnitine acetyltransferase & $21 \pm 10$ & $137 \pm 53$ \\
\hline Fatty acid synthase & $36 \pm 18$ & nil \\
\hline Malic enzyme & $103 \pm 30$ & $69 \pm 28$ \\
\hline Pyruvate kinase & $921 \pm 482$ & $97 \cdot 6 \pm 21 \cdot 0$ \\
\hline $\begin{array}{l}\text { Glucose-6-phosphate } \\
\text { dehydrogenase }\end{array}$ & $529 \pm 126$ & $179 \pm 46$ \\
\hline
\end{tabular}

via acetyl-CoA rather than pyruvate (Schwitzguébel et al., 1981). This pathway serves to replenish the shortfall of $\mathrm{C}_{4}$ citric acid cycle intermediates, which occurs due to diversion of carbon from the citric acid cycle for biosynthesis. Isocitrate lyase was absent from Mort. alpina grown on glucose but was detected when the fungus was grown on Tween 80 (Table 2). The appearance of isocitrate lyase confirms that growth on Tween 80 induces the activity of the glyoxylate cycle; this would be expected, as fatty acids are metabolized via acetyl-CoA.

ATP:citrate lyase. This is a cytosolic enzyme that is involved in the generation of cytosolic acetyl-CoA from citrate after its export from the mitochondria (Boulton \& Ratledge, 1983). The enzyme was detected in Mort. alpina when glucose was the carbon source, in accord with previous findings (Wynn et al., 1998), indicating a flux of carbon from the mitochondria for biosynthesis. When the fungus was grown on Tween 80 , however, no ATP : citrate lyase activity was detected. $\beta$-Oxidation of fatty acids in the glyoxysomes/peroxisomes of fungi liberates acetyl-CoA, which is translocated to the mitochondria for energy generation. As a result, when Mort. alpina was grown on a fatty-acid-based carbon source, the acetyl-CoA flux was into, not out of the mitochondria; ATP: citrate lyase activity was therefore not required in such cells and was completely repressed.

Carnitine acetyltransferase. This is an enzyme involved in the translocation of acetyl-CoA inside the cell. In contrast to the energy-dependent export of acetyl-CoA from the mitochondria (culminating in the cleavage of citrate by ATP: citrate lyase to yield cytosolic acetyl$\mathrm{CoA}$ ), carnitine acetyltransferase is involved in a more general shuttling of acetyl-CoA between cellular compartments (Kohlaw \& Tan-Wilson, 1977). This enzyme was detected in glucose-grown Mort. alpina, in accord with previous observations (Wynn et al., 1998), but its activity was increased sevenfold when Tween 80 was the carbon source. The elevated activity of this enzyme was a result of the increased requirement for acetyl-CoA transportation between cellular compartments in cells grown on a fatty-acid-based carbon source.

The changes in the activities of this enzyme, and of isocitrate lyase and ATP:citrate lyase, confirm that when Mort. alpina was cultivated on Tween 80, the metabolism of the fungus underwent changes identical to those previously described when both oleaginous yeasts and filamentous fungi were grown on exogenous triacylglycerol oils (Holdsworth et al., 1988; Wynn, 1994).

Fatty acid synthase. Whilst activity of fatty acid synthase was readily detected in glucose-grown cells, indicating active de novo fatty acid biosynthesis, cells grown on Tween 80 were devoid of this enzyme activity. That the inactivity of fatty acid synthase in extracts from Tweengrown biomass was not the result of trace amounts of Tween being 'carried over' into the extracts and inhibiting this enzyme was demonstrated by direct addition of Tween 40 and Tween 80 to the in vitro fatty acid synthase assay. Neither Tween 40 nor Tween 80 inhibited fatty acid synthase activity at $0 \cdot 1 \%(\mathrm{w} / \mathrm{v})$. The lack of fatty acid synthase activity in extracts from Tween-grown biomass was clear evidence of the cessation of de novo fatty acid synthesis in cells grown on a fatty-acid-based carbon source.

As the cessation of de novo fatty acid biosynthesis when Mort. alpina was grown on fatty-acid-based carbon sources is important in the evaluation of the lipid analysis data given below, the fatty acid synthase activity when the fungus was grown on Tween 20 and 40 was also determined. In all cases, when Tween compounds were the carbon source, fatty acid synthase activity was undetectable.

That no fatty acid synthesis was occurring precluded the possibility of the appearance of PUFAs as a result of de novo synthesis rather than transformation of exogenous fatty acids, as has previously been suggested (Kendrick \& Ratledge, 1996; Certik et al., 1997).

Malic enzyme. Although activity of this enzyme has been detected in a number of filamentous fungi its cellular function remains contentious. In Aspergillus nidulans, where the activity of malic enzyme is low when glucose is the carbon source (McCullough \& Roberts, 1974; Wynn \& Ratledge, 1997), this enzyme appears vital for the provision of pyruvate to allow growth on carbon sources metabolized via acetyl-CoA (including lipids) (McCullough \& Roberts, 1974). Evidence has been obtained in this laboratory to suggest that malic enzyme in filamentous fungi, and in the zygomycetes in particular, is crucial for cell lipid biosynthesis (Wynn \& Ratledge, 1997; Wynn et al., 1997, 1999).

When Mort.alpina was grown on glucose the activity of malic enzyme was relatively high (Table 2), tenfold greater than in Asp. nidulans (Wynn \& Ratledge, 1997). 
Growth of Mort. alpina on Tween 80 led to a decrease in malic enzyme activity. [The overlapping errors shown in Table 2 were a result of inter-experiment variability. During the five occasions that malic enzyme was measured in glucose- and Tween 80-grown biomass (grown at the same time, from the same inoculum) the malic enzyme activity was less in the Tween 80-grown cells on four occasions, whilst being equivalent in the fifth.] That malic enzyme activity decreased when Mort. alpina was grown on Tween 80, together with its high activity in glucose-grown cells, suggested that the major cellular role of this enzyme is not in the provision of pyruvate when the fungus is grown on carbon sources such as fatty acids that are metabolized via acetyl-CoA and therefore require the glyoxylate bypass for metabolism. In this regard Mort. alpina may be similar to Fusarium oxysporum and Neurospora crassa, where a decrease in the activity of malic enzyme was observed when these fungi were grown on acetate (Zink, 1972; Zink \& Katz, 1973). The residual activity of malic enzyme ( $\approx 70 \%$ of that in glucose-grown cells) in Mort. alpina grown on Tween 80 suggests that malic enzyme fulfils another role as well as providing NADPH for fatty acid de novo synthesis. As fatty acid metabolism (although not de novo synthesis) continued in cells grown on Tween 80 (see below) it is suggested that malic enzyme in Mort. alpina may be acting as a provider of $\mathrm{NADPH}$ for fatty acid desaturation, as has been suggested by Kendrick \& Ratledge (1992) with Mucor circinelloides, and even fatty acid elongation.

Pyruvate kinase. Activity of this enzyme was detected at $\approx 1000 \mathrm{nmol} \mathrm{min}^{-1}(\mathrm{mg} \text { protein })^{-1}$ in glucose-grown cells, but was decreased by $90 \%$ when Mort. alpina was grown on Tween 80 (Table 2). These observations are similar to those of McCullough \& Roberts (1974) for Asp. nidulans grown on either glucose or acetate. McCullough \& Roberts (1974) surmised that the residual pyruvate kinase activity was not involved in the provision of pyruvate for biosynthesis in Asp. nidulans. It was hypothesized that malic enzyme activity (which increased under these conditions) was responsible for the generation of pyruvate needed for biosynthetic purposes. It appears that the primary role of malic enzyme in Mort. alpina and Asp. nidulans may differ, as evidenced by the far higher activity of malic enzyme in glucose-grown cells of Mort. alpina than in Asp. nidulans (McCullough \& Roberts, 1974; Wynn \& Ratledge, 1997; Wynn et al., 1999) and by the decrease rather than increase in malic enzyme when Mort. alpina is grown on carbon sources that induce the glyoxylate shunt. We therefore propose that in Mort. alpina, as in Mr. circinelloides (Wynn et al., 1997, 1999), malic enzyme's primary function is the provision of NADPH for fatty acid synthesis and that biosynthetic pyruvate is probably generated by the residual pyruvate kinase activity.

Glucose-6-phosphate dehydrogenase. This is a marker enzyme for the hexose monophosphate pathway that acts to synthesize ribose for nucleic acids and erythrose 4-phosphate for synthesis of aromatic amino acids, which must still continue in lipid-utilizing cells, as well as generating NADPH for anabolism. The lower activity of glucose-6-phosphate dehydrogenase in Mort. alpina cultivated on Tween 80 undoubtedly reflected the decreased carbon flux through the hexose monophosphate pathway when cells are grown on exogenous oils.

\section{Growth and lipid production in Mort. alpina grown on glucose and Tween carbon sources}

The problems of determining the fatty acyl composition of fungi when cultivated on lipids are principally those of removing exogenous lipid that adheres to the surface of the mycelia. These have been highlighted elsewhere (Kendrick \& Ratledge, 1996; Certik et al., 1997). The use of various Tweens as carbon sources during the present work has overcome these problems. Tween detergents are fatty-acid-based compounds that have the advantage of being water-soluble and can be easily washed off the cells at the end of growth. The Tweens are also easily hydrolysed to their constituent fatty acids and sorbitan, which is a non-metabolizable carbohydrate. Therefore if the fungus can hydrolyse the Tweens and is seen to grow on these carbon sources then it must be using the fatty acids as the sole source of carbon. That Mort. alpina was utilizing the fatty acid component of the Tweens as a carbon source was confirmed by the changes in the enzymology of the fungus (see above). The water solubility of the Tweens and their removal from the mycelia using an aqueous wash was important as it obviated the need for an organic solvent wash as employed in previous studies (Kendrick \& Ratledge, 1996; Certik et al., 1997). An organic solvent wash has the potential to remove some of the intracellular lipid and, in any case, was undesirable for biomass destined for enzymological study.

Growth of Mort. alpina on Tween carbon sources resulted in less biomass being obtained than when glucose was the carbon source (see Table 3); however, the cell lipid content was greatly increased. The fatty acyl profiles of the cell lipids when Mort. alpina was grown on the Tween carbon sources were similar but, significantly, not identical, to those of the Tweens themselves (shown in Table 1). Although the cell lipids were not as unsaturated as those in glucose-grown biomass (see Table 3) they had higher unsaturation indexes than the starting carbon source and contained higher amounts of $18: 2(n-6)$ as well as significant amounts of the PUFAs $18: 3(n-6)$ and $20: 4(n-6)$, which were entirely absent from the Tween carbon sources (see Table 1). Thus growth on a lipid carbon source did not inhibit fatty acid desaturation and elongation even though complete repression of fatty acid synthesis occurred (Table 2). This is in accord with the data reported by Shimizu et al. (1989a, b), Shinmen et al. (1992) and Certik et al. (1997), but which were equivocal because of the possibility of residual substrates still being present or that mixed fatty acids in the substrate could be taken up at different rates, which would result in observed differences in the fatty acid profiles of the 
Table 3. Growth and lipid production of Mort. alpina cultivated on glucose and Tween 80

Biomass was cultivated in shake-flasks for $4 \mathrm{~d}$ at $30^{\circ} \mathrm{C}$ on a defined medium containing either $30 \mathrm{~g}$ glucose $1^{-1}$ or $16 \mathrm{~g}$ Tween $1^{-1}$ as the carbon source. Experiments were carried out in triplicate and means \pm standard error of the mean are presented. tr., trace.

\begin{tabular}{|c|c|c|c|c|}
\hline & \multicolumn{4}{|c|}{ Carbon source } \\
\hline & Glucose & Tween 20 & Tween 40 & Tween 80 \\
\hline Cell dry wt $\left(\mathrm{g} \mathrm{l}^{-1}\right)$ & $3 \cdot 1 \pm 0 \cdot 5$ & $0 \cdot 3 \pm 0 \cdot 2$ & $0 \cdot 6 \pm 0 \cdot 2$ & $0 \cdot 7 \pm 0 \cdot 5$ \\
\hline Cell lipid $(\%, w / w$, dry wt $)$ & $19 \cdot 3 \pm 1 \cdot 2$ & $32 \cdot 5 \pm 2 \cdot 5$ & $35 \cdot 5 \pm 5 \cdot 9$ & $39 \cdot 4 \pm 6 \cdot 2$ \\
\hline Fatty acyl residue & \multicolumn{4}{|c|}{ Relative $\%(w / w)$ total fatty acids } \\
\hline $12: 0$ & tr. & $13 \cdot 9 \pm 1 \cdot 9$ & tr. & tr. \\
\hline $14: 0$ & $1 \cdot 8 \pm 0 \cdot 1$ & $19 \cdot 2 \pm 2 \cdot 2$ & $2 \cdot 0 \pm 0 \cdot 2$ & $2 \cdot 8 \pm 0 \cdot 5$ \\
\hline $16: 0$ & $15 \cdot 9 \pm 0 \cdot 1$ & $15 \cdot 1 \pm 0 \cdot 8$ & $41 \cdot 4 \pm 2 \cdot 4$ & $5 \cdot 6 \pm 0 \cdot 2$ \\
\hline $16: 1$ & tr. & tr. & $3 \cdot 4 \pm 2 \cdot 1$ & $10 \cdot 3 \pm 1 \cdot 6$ \\
\hline $18: 0$ & $13 \cdot 1 \pm 1 \cdot 8$ & $9 \cdot 0 \pm 2 \cdot 5$ & $3 \cdot 3 \pm 1 \cdot 7$ & $1 \cdot 0 \pm 1 \cdot 5$ \\
\hline $18: 1$ & $24 \cdot 2 \pm 2 \cdot 1$ & $20 \cdot 6 \pm 3 \cdot 4$ & $21 \cdot 6 \pm 2 \cdot 7$ & $57 \cdot 8 \pm 1 \cdot 1$ \\
\hline $18: 2$ & $7 \cdot 6 \pm 0 \cdot 9$ & $5 \cdot 4 \pm 1 \cdot 4$ & $7 \cdot 7 \pm 1 \cdot 2$ & $4 \cdot 5 \pm 0 \cdot 7$ \\
\hline $18: 3(n-6)$ & $4 \cdot 0 \pm 0 \cdot 8$ & $3 \cdot 2 \pm 1 \cdot 2$ & $5 \cdot 2 \pm 0 \cdot 9$ & $3 \cdot 8 \pm 0 \cdot 5$ \\
\hline $20: 3(n-6)$ & $3 \cdot 0 \pm 0 \cdot 8$ & $1 \cdot 3 \pm .03$ & $1 \cdot 1 \pm 0 \cdot 1$ & $0 \cdot 9 \pm 0 \cdot 0$ \\
\hline $20: 4(n-6)$ & $18 \cdot 2 \pm 2 \cdot 0$ & $6 \cdot 7 \pm 4 \cdot 1$ & $12 \cdot 2 \pm 1 \cdot 4$ & $6 \cdot 6 \pm 2 \cdot 5$ \\
\hline $\mathrm{UI}^{*}$ & $1 \cdot 30 \pm 0 \cdot 10$ & $0 \cdot 71 \pm 0 \cdot 27$ & $0 \cdot 89 \pm 0.30$ & $1 \cdot 13 \pm 0 \cdot 08$ \\
\hline
\end{tabular}

$\mathrm{UI}=$ unsaturation index $=[(\%$ monoene $+2(\%$ diene $)+3(\%$ triene $)+4($ tetraene $)] / 100$.

substrate and the cell lipid recovered from the biomass (Kendrick \& Ratledge, 1996; Certik et al., 1997). That conversion of $16: 0$, and even $12: 0$, into $\mathrm{C}_{18}$ and $\mathrm{C}_{20}$ fatty acids occurred in Mort. alpina lacking fatty acid synthase activity indicated that the fatty acid elongation system was capable of accepting relatively short-chain fatty acids as well as long-chain fatty acids. A similarly flexible elongation system has also been demonstrated in yeasts (Dittrich et al., 1998).

At first inspection the results presented in Table 3 appear to indicate diminished synthesis of $20: 3(n-6)$ and $20: 4(n-6)$ and possibly even $18: 3(n-6)$ in the Tweengrown cells. However, this interpretation ignores the substantial increase in cell lipid as a consequence of the incorporation of fatty acids from the substrates. To take the increased lipid contents in Tween-grown cells into account the data in Table 3 were recalculated as the amount of fatty acid produced per unit of lipid-free dry weight (i.e. without inclusion of the mass of lipid). This we designated the 'biosynthetic capacity' of the fungus to produce each fatty acid under the prevailing growth conditions.

These results (see Table 4) allow the biosynthetic capacity of the Tween-grown cells to be compared on an equal basis with that of the glucose-grown cells. The inclusion of an internal standard in the calculation of total cell lipid and therefore the biosynthetic capacities was important to avoid the potential for non-lipid material (e.g. sterols, carotenoids and other nonsaponifiable lipids) extracted with cell lipid affecting the calculation. It was found that lipid analyses carried out both with and without an internal standard gave essentially identical results, indicating that there was no substantial change in the non-fatty acid components of the total lipid when glucose or Tween was the carbon source.

The biosynthetic capacities of Mort. alpina for the production of arachidonic acid $[20: 4(n-6)]$ and its immediate precursor 20:3(n-6) appeared to be unaffected by the carbon source (see Table 4). The increase in 20:4(n-6) when Tween 40 was the carbon source was not significant. However, the analysis of Tween-grown cells demonstrated a significantly increased biosynthetic capacity for both $18: 2(n-6)$ (by $50-150 \%$ ) and $18: 3(n-6)$ (by $100-150 \%$ ) relative to that in glucose-grown cells. This suggested that the $\Delta 12$ desaturase, converting $18: 1(n-9)$ to $18: 2$, and the $\Delta 6$ desaturase, converting $18: 2(n-6)$ to $18: 3(n-6)$, were capable of converting increased amounts of $18: 1$ and $18: 2$, respectively, but that the elongation of $18: 3(n-6)$ to $20: 3(n-6)$ was rate-limiting, as there was no significant increase in the capacity of the cells to produce $20: 4(n-6)$ or $20: 3(n-6)$ when cells grown on Tweens were compared with cells grown on glucose.

It therefore appears that in the overall conversion of oleic acid to arachidonic acid it is the elongase activity that is the rate-limiting step in the biosynthesis of $20: 4(n-6)$. Attempts to increase the productivity of 20:4(n-6) formation in commercial strains of Mort. alpina should therefore focus on increasing the elongase 
Table 4. Fatty acid biosynthetic capacity of Mort. alpina grown on different carbon sources

The biosynthetic capacity data were calculated from the data in Table 3. Biosynthetic capacity represents the amount of fatty acid produced per unit lipid-free biomass, and is calculated as: $[(\%$ fatty acid $) \times(\%$ cell lipid $/ 100)] .[100 /(100-\%$ cell lipid $)]$.

\begin{tabular}{|lcccc|}
\hline \multirow{2}{*}{ Fatty acid } & \multicolumn{4}{c}{ Biosynthetic capacity [mg fatty acid (g lipid free dry wt) } \\
& \multicolumn{4}{c|}{ of biomass after growth on: } \\
\cline { 2 - 5 } & Glucose & Tween $\mathbf{2 0}$ & Tween $\mathbf{4 0}$ & Tween 80 \\
& $0 \cdot 2 \pm 0 \cdot 2$ & $62 \cdot 9 \pm 3 \cdot 5$ & $0 \cdot 4 \pm 0 \cdot 6$ & $0 \cdot 0 \pm 0 \cdot 0$ \\
$12: 0$ & $4 \cdot 2 \pm 0 \cdot 7$ & $87 \cdot 5 \pm 16 \cdot 9$ & $10 \cdot 7 \pm 2 \cdot 8$ & $18 \cdot 8 \pm 10 \cdot 0$ \\
$14: 0$ & $37 \cdot 2 \pm 3 \cdot 5$ & $68 \cdot 2 \pm 1 \cdot 7$ & $217 \cdot 3 \pm 61 \cdot 9$ & $36 \cdot 7 \pm 11 \cdot 8$ \\
$16: 0$ & $30 \cdot 4 \pm 1 \cdot 1$ & $40 \cdot 5 \pm 8 \cdot 2$ & $15 \cdot 9 \pm 2 \cdot 9$ & $5 \cdot 1 \pm 7 \cdot 2$ \\
$18: 0$ & $58 \cdot 2 \pm 9 \cdot 2$ & $100 \cdot 3 \pm 26 \cdot 7$ & $123 \cdot 1 \pm 42 \cdot 2$ & $382 \cdot 8 \pm 104 \cdot 1$ \\
$18: 1$ & $18 \cdot 1 \pm 1 \cdot 1$ & $26 \cdot 8 \pm 9 \cdot 4$ & $43 \cdot 8 \pm 15 \cdot 9$ & $29 \cdot 9 \pm 9 \cdot 1$ \\
$18: 2$ & $9 \cdot 6 \pm 2 \cdot 0$ & $15 \cdot 9 \pm 7 \cdot 0$ & $28 \cdot 1 \pm 2 \cdot 9$ & $24 \cdot 6 \pm 3 \cdot 5$ \\
$18: 3(n-6)$ & $6 \cdot 8 \pm 1 \cdot 2$ & $6 \cdot 7 \pm 0 \cdot 4$ & $6 \cdot 8 \pm 0 \cdot 3$ & $6 \cdot 7 \pm 1 \cdot 0$ \\
$20: 3(n-6)$ & $43 \cdot 5 \pm 3 \cdot 6$ & $33 \cdot 9 \pm 23 \cdot 6$ & $69 \cdot 1 \pm 22 \cdot 5$ & $44 \cdot 7 \pm 21 \cdot 2$ \\
$20: 4(n-6)$ & & & & \\
\hline
\end{tabular}

activity (presumably by genetic manipulation) rather than on increasing the $\Delta 12$ and $\Delta 6$ desaturases, which seemingly have an inherent capacity to desaturate twice the amount of substrate they normally handle. Even increasing the activity of the final $\Delta 5$ desaturase for the conversion of $20: 3(n-6)$ to $20: 4(n-6)$ would probably not increase the final yield of arachidonic acid significantly.

\section{Conclusions}

The data obtained when Mort. alpina was grown on Tween carbon sources shed light on two different aspects of the biochemistry of this fungus.

The analysis of the enzyme activities when Mort. alpina was cultivated on Tween compounds indicates that de novo fatty acid biosynthesis is abolished (repressed) by growth of cells on exogenous lipid.

The changes in the composition of the cell lipid indicate that Mort. alpina incorporates and modifies exogenous fatty acids into its own cell lipid. Neither fatty acid desaturation nor elongation is repressed under these conditions. The analysis of oleate incorporation implicates the elongase converting $18: 3(n-6)$ to $20: 3(n-6)$ as the rate-limiting step in arachidonic acid biosynthesis, rather than any fatty acid desaturase. This could have important implications when attempting to increase $20: 4(n-6)$ production in genetically modifiable systems.

Also it appears likely that the provision of pyruvate for alanine biosynthesis during growth on fatty acids could be fulfilled by a residual activity of pyruvate kinase (i.e. from the phosphoenolpyruvate synthesized from oxaloacetate). The major function of malic enzyme, which is the sole enzyme activity associated with lipogenesis in this fungus (Wynn et al., 1999), would be the generation of NADPH for lipid biosynthesis. Under conditions of growth on lipids the residual activity of malic enzyme would provide NADPH for the continuing fatty acid desaturation and elongation.

\section{ACKNOWLEDGEMENTS}

Throughout this work J.P.W. was supported by a BBSRC Link grant in collaboration with Avecia, Roche and Newtec Laboratories. Expert technical assistance was provided by Mrs Maureen Ewing.

\section{REFERENCES}

Armitt, S., McCullough, W. \& Roberts, C. F. (1976). Analysis of acetate non-utilizing mutants in Aspergillus nidulans. J Gen Microbiol 92, 263-282.

Boulton, C. A. \& Ratledge, C. (1983). Partial purification and some properties of ATP:citrate lyase from the oleaginous yeast Lipomyces starkeyi. J Gen Microbiol 129, 2863-2869.

Butte, W. (1983). Rapid method for the determination of fatty acid profiles from fats and oils using trimethylsulphonium hydroxide for transesterification. J Chromatogr 261, 142-145.

Certik, M., Balteszova, L. \& Sajbidor, J. (1997). Lipid formation and $\gamma$-linolenic acid production by Mucorales fungi grown on sunflower oil. Lett Appl Microbiol 25, 101-105.

Dittrich, F., Zajonc, D., Hühne, K. \& 8 other authors (1998). Fatty acid elongation in yeast: biochemical characteristics of the enzyme system and isolation of elongation-defective mutants. Eur J Biochem 252, 477-485.

Folch, J., Less, M. \& Sloane-Stanley, G. H. (1957). A simple method for the isolation and purification of total lipides from animal tissues. J Biol Chem 226, 497-509.

Gill, I. \& Valivety, R. (1997). Polyunsaturated fatty acids, part 1: occurrence, biological activities and applications. Trends Biotechnol 15, 401-409.

Holdsworth, J. E., Veenhuis, M. \& Ratledge, C. (1988). Enzyme activities in oleaginous yeasts accumulating and utilizing exogenous or endogenous lipids. J Gen Microbiol 134, 2907-2915. 
Kawamoto, S., Ueda, M., Nozaki, C., Yamamura, M., Tanaka, A. \& Fukui, S. (1978). Localization of carnitine acetyltransferase in peroxisomes and in mitochondria of n-alkane grown Candida tropicalis. FEBS Lett 96, 37-40.

Kendrick, A. \& Ratledge, C. (1992). Desaturation of polyunsaturated fatty acids in Mucor circinelloides and the involvement of the novel membrane-bound malic enzyme. Eur J Biochem 209, 667-673.

Kendrick, A. \& Ratledge, C. (1996). Cessation of polyunsaturated fatty acid formation in four selected filamentous fungi when grown on plant oils. J Am Oil Chem Soc 73, 431-435.

Kohlaw, G. B. \& Tan-Wilson, A. (1977). Carnitine acetyltransferase: candidate for the transfer of acetyl groups through the mitochondrial membrane of yeast. J Bacteriol 129, 1159-1161.

Kyle, D. J. (1997). Production and use of a single cell oil highly enriched in arachidonic acid. Lipid Technol 9, 116-121.

McCullough, W. \& Roberts, C. F. (1974). The role of malic enzyme in Aspergillus nidulans. FEBS Lett 41, 238-242.

Ratledge, C. (1992). Microbial lipids: commercial realities or academic curiosities. In Industrial Applications of Single Cell Oils, pp. 1-15. Edited by D. Kyle \& C. Ratledge. Champaign: AOCS Press.

Ratledge, C. (1997). Microbial lipids. In Biotechnology, vol. 7, Products of Secondary Metabolism, 2nd edn, pp. 135-197. Edited by H. Kleinkauf \& H. von Dohren. Weinheim: VCH.

Rodriguez-Ruiz, J., Belarbi, E., Sanchez, J. L. G. \& Alonso, D. L. (1998). Rapid simultaneous lipids extraction and transesterification for fatty acid analyses. Biotechnol Tech 12, 689-691.

Schwitzguébel, J. P., Møller, I. M. \& Palmer, J. M. (1981). Changes in density of mitochondria and glyoxysomes from Neurospora crassa: a re-evaluation utilizing silica sol gradient centrifugation. J Gen Microbiol 126, 289-295.

Shimizu, S., Kawashima, H., Akimoto, K., Shinmen, Y. \& Yamada, H. (1989a). Conversion of linseed oil to a eicosapentaenoic acid- containing oil by Mortierella alpina IS-4 at low temperature. Appl Microbiol Biotechnol 32, 1-4.

Shimizu, S., Kawashima, H., Akimoto, K., Shinmen, Y. \& Yamada, H. (1989b). Microbial conversion of an oil containing $\alpha$-linolenic acid to an oil rich in eicosapentaenoic acid. J Am Oil Chem Soc 66, 342-347.

Shinmen, Y., Kawashima, H., Shinmen, S. \& Yamada, H. (1992). Concentration of eicosapentaenoic acid and docosapentaenoic acid in an arachidonic acid-producing fungus, Mortierella alpina IS-4, grown with fish oil. Appl Microbiol Biotechnol 38, 301-304.

Worthington Enzymes (1979). Pyruvate kinase. In Enzymes and Related Biochemicals, pp. 179-180. Bedford, MA: Millipore.

Wynn, J. P. (1994). Intermediary metabolism of Fusarium moniliforme. PhD thesis, University of Hull.

Wynn, J. P. \& Ratledge, C. (1997). Malic enzyme is a major source of NADPH for lipid accumulation in Aspergillus nidulans. Microbiology 143, 253-257.

Wynn, J. P., Kendrick, A. \& Ratledge, C. (1997). Sesamol as an inhibitor of growth and lipid metabolism in Mucor circinelloides via its action on malic enzyme. Lipids 32, 605-610.

Wynn, J. P., Hamid, A. A., Midgley, M. \& Ratledge, C. (1998). Widespread occurrence of ATP:citrate lyase and carnitine acetyltransferase in filamentous fungi. World J Microbiol Biotechnol 14, 145-147.

Wynn, J. P., Hamid, A. A. \& Ratledge, C. (1999). The role of malic enzyme in the regulation of lipid accumulation in filamentous fungi. Microbiology 145, 1911-1917.

Zink, M. W. (1972). Regulation of the two 'malic' enzymes in Neurospora crassa. Can J Microbiol 18, 611-617.

Zink, M. W. \& Katz, J.S. (1973). Malic enzyme of Fusarium oxysporum. Can J Microbiol 19, 1187-1196.

Received 16 February 2000; revised 5 May 2000; accepted 5 June 2000 